\title{
Role of Strontium on the Crystallization of Calcium Hydrogen Phosphate Dihydrate (CHPD)
}

\author{
K. Suguna ${ }^{1,2}$, C. Sekar ${ }^{3 *}$ \\ ${ }^{1}$ Department of Physics, Sri Sarada College for Women, Salem -636 016, TN, India. \\ ${ }^{2}$ Department of Physics, Periyar University, Salem- 636 011, TN, India. \\ ${ }^{3}$ Department of Bioelectronics and Biosensors, Alagappa University, \\ Karaikudi-630003, TN, India. \\ *Corresponding Author: Sekar2025@gmail.com
}

\begin{abstract}
Calcium hydrogen phosphate dihydrate $\left(\mathrm{CHPD}, \mathrm{CaHPO}_{4} \cdot 2 \mathrm{H} 2 \mathrm{O}\right)$ or brushite is found quite frequently in urinary calculi (stones). Crystallization of brushite has been carried out in sodium metasilicate (SMS) gel with and without adding 'Sr' as additive. In pure system, dicalcium phosphate anhydrous (DCPA, CaHPO$\left.)_{4}\right)$ or monetite and hydroxyapatite (HA, $\left.\mathrm{Ca}_{5}\left(\mathrm{PO}_{4}\right)_{3}(\mathrm{OH})\right)$ grew along with brushite. The presence of $\mathrm{Sr}$ suppressed the formation of $H A$ and enhanced the number and size of monetite crystals and changed the morphology of brushite crystals from needle shape to octopus-like shape. The samples were characterized by powder \& single crystal X-ray diffraction (XRD), scanning electron microscopy (SEM), Xray fluorescence spectroscopy $(X R F)$, Fourier transform infrared spectroscopy $(F T I R)$ and thermal analyses (TG-DTA).
\end{abstract}

Keywords: Brushite, Crystal growth, Sr additive, SEM.

\section{INTRODUCTION}

Calcium phosphates have been studied extensively because of their occurrence in normal and pathological calcifications. Due to their excellent biocompatibility, it is a well-known bioactive material suitable for bone and hard tissue replacement ${ }^{[1]}$. Hydroxyapatite (HA, $\mathrm{Ca}_{5}\left(\mathrm{PO}_{4}\right)_{3}(\mathrm{OH})$, octacalcium phosphate $\left(\mathrm{OCP}, \mathrm{Ca}_{8} \mathrm{H}_{2}\left(\mathrm{PO}_{4}\right)_{6} \cdot 5\left(\mathrm{H}_{2} \mathrm{O}\right)\right)$, tricalcium phosphate $(\beta-$ TCP, $\left.\mathrm{Ca}_{3}\left(\mathrm{PO}_{4}\right)_{2}\right)$, dicalcium phosphate dihydrate or calcium hydrogen phosphate dihydrate $\left(\mathrm{CHPD}, \mathrm{CaHPO}_{4} \cdot 2 \mathrm{H}_{2} \mathrm{O}\right)$, dicalcium phosphate anhydrous (DCPA, CaHPO4), tetracalcium phosphate (TTCP, $\left.\mathrm{Ca}_{4}\left(\mathrm{PO}_{4}\right)_{2} \mathrm{O}\right)$ and amorphous calcium phosphate $(\mathrm{ACP})^{[2]}$ are different 
crystalline calcium phosphates that have applications in biological mineralization. Brushite phase is mostly found in callus, bone, and kidney stones ${ }^{[3]}$.

Investigations of the urinary stones showed large number of trace elements including $\mathrm{Cd}, \mathrm{Pb}$, $\mathrm{Zn}, \mathrm{Mg}, \mathrm{Sr}, \mathrm{Cr}, \mathrm{Mn}, \mathrm{Ni}, \mathrm{Co}, \mathrm{Cu}, \mathrm{Au}, \mathrm{Tl}, \mathrm{Bi}$ etc., along with the main constituents ${ }^{[4]}$. An increase in the level of the trace element in the body fluid leads to the crystal deposition which results in the development of kidney stones ${ }^{[5]}$.

Lundager Madsen ${ }^{[6]}$ investigated the influence of 14 different di- and trivalent metal ions on brushite formation and reported that some ions inhibit and some ions promote the formation of brushite. Sekar et al. ${ }^{[7]}$ reported that the fluoride addition reduces the size and total number of brushite crystals. The presence of magnesium reported to inhibit the formation of brushite crystals ${ }^{[8]}$. LeGeros ${ }^{[9]}$ grew single crystals of brushite in silica gel, and reported that the presence of $\mathrm{Sr}^{2+}$ and $\mathrm{P}_{2} \mathrm{O}_{7}{ }^{4-}$ causes marked effect on the crystal habit. Addition of $\mathrm{Sr}^{2+}$ changed the morphology from usual platelet to spiral aggregate and the presence of $\mathrm{P}_{2} \mathrm{O}_{7}{ }^{4-}$ led to the growth of small needle- shaped crystals.

The intake of Sr per day through food and fluids is $1.9 \mathrm{mg}$. In that the loss in urine is 0.34 $\mathrm{mg}$, loss in feces is $1.5 \mathrm{mg}$, loss in sweat is $0.02 \mathrm{mg}$, and hair is $0.2 \times 10^{-3} \mathrm{mg}{ }^{[10]}$. Strontium renalate is a recommended medication for osteoporosis which is found to increase the risk of stone formation in the patients ${ }^{[11]}$. These issues are important because, in the case of kidney stones, the medical treatment depends strongly on the precise chemical phase and on the morphology of the biological entities ${ }^{[12]}$. So the objective of the present study is to explore the role of $\mathrm{Sr}$ on the crystallization and properties of CHPD in gel medium. Because of viscous nature of the gel medium, it provides an in vitro model for crystallization of biomolecules ${ }^{[13]}$.

\section{EXPERIMENTAL}

\subsection{Preparation}

The crystallization was carried out in glass test tubes of $25 \mathrm{~mm}$ diameter and $150 \mathrm{~mm}$ length. The chemicals used were AR grade $\mathrm{SrCl}_{2}, \mathrm{CaCl}_{2}$ and orthophosphoric acid. The SMS gel was prepared as described in the literature ${ }^{[14]}$. One of the reactants, orthophosphoric acid $(1 \mathrm{M})$ was mixed with silica gel of density $1.06 \mathrm{gm} / \mathrm{cm}^{3}$ so that the $\mathrm{pH}$ of the mixture could be set to 6.0. The mixture was then transferred into test tubes. After gelation, the supernatant solution calcium chloride $(1 \mathrm{M})$ was slowly added along the walls of the test tubes. To study the effect of strontium, $\mathrm{SrCl}_{2}(0.1 \& 0.2 \mathrm{M})$ was mixed with calcium chloride and the experiments were repeated as described above. After three weeks the crystals were harvested and characterized.

Powder X-ray diffraction pattern was recorded on Bruker advance diffractometer within the $2 \theta$ range of 10 to $70^{\circ}$. The elemental composition of the specimen was determined using an elemental analyzer JEOL JSX 3222 equipped with energy dispersive X-ray fluorescence 
system (XRF). The surface morphology of the samples was evaluated by scanning electron microscopy (SEM). Thermal analyses were performed using SDT Q600 V8.3 Build 101 instrument. FTIR spectra of the grown crystals were recorded using Perkin Elmer, Spectrum $\mathrm{Rx} 1$ detector and $\mathrm{KBr}$ beam splitter.

\section{RESULTS AND DISCUSSION}

\subsection{Crystal growth}

A systematic investigation has been carried out to understand the role of strontium on the crystallization of calcium phosphates under physiological conditions. Two different amount of ' $\mathrm{Sr}$ ' was added in the form of $\mathrm{SrCl}_{2}$ to the growth environment. In all the cases, a white precipitate has formed at the gel- solution interface within 12 minutes of adding supernatant solution. White colored rings known as Liesegang rings have appeared just below the interface within 6 hours. The number of these white colored rings increased with time and a total of 16 such rings were observed after five days. In the mean time, the first few Liesegang rings started dissolving slowly and tiny white spherulites have grown in that place. The colorless and transparent needle shaped crystals have grown in between the Liesegang rings. Approximately 10-15 needle shaped crystals were harvested after three weeks. Figs.1a and 1b show the crystals grown in test tubes without and with $(0.1 \mathrm{M})$ addition of $\mathrm{Sr}$.

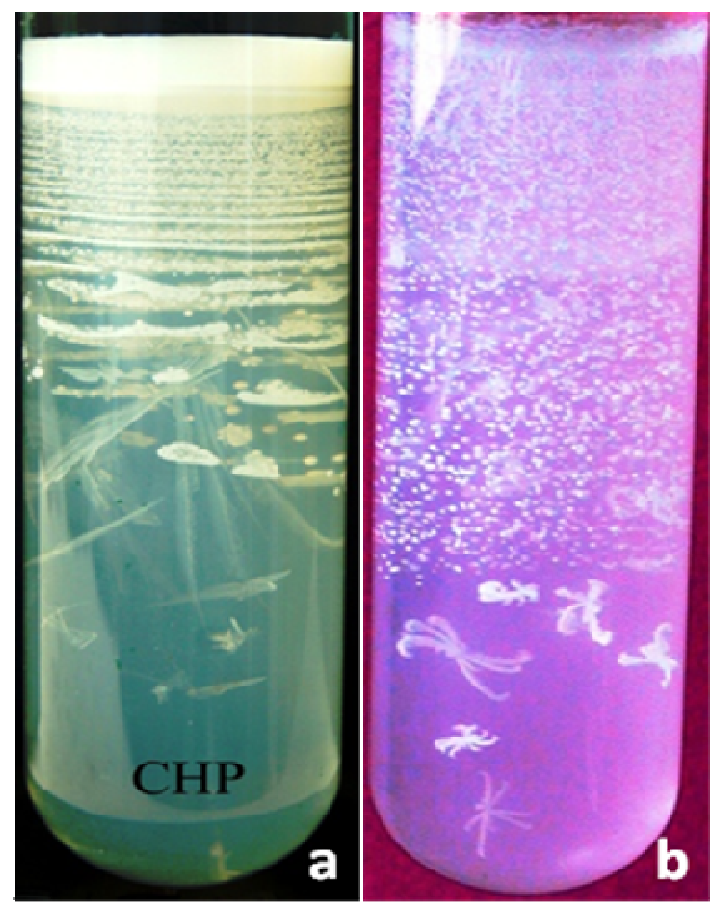

Fig. 1. Calcium phosphate crystals in the test tubes (a) pure (b) $0.2 \mathrm{M} \mathrm{SrCl}_{2}$ added 
In strontium $(0.1 \mathrm{M})$ added experiments, the growth pattern was completely different. After adding the supernatant solutions white precipitate was observed just below the interface. After three days, white spherulites have appeared from the middle towards the bottom of the tube as shown in Fig.1b. The number and size of spherulitic crystals increased with time. Simultaneously a few tiny crystallites have appeared in the lower end of the gel medium which continued to grow and assumed the coral (octopus) like morphology ${ }^{[15]}$. Figs. 2a and $2 \mathrm{~b}$ show the needle and octopus like crystal grown without and with strontium addition. Contrary to the pure system, Liesegang rings did not appear and there was no detectable amount of white precipitate at the interface between supernatant solution and gel. As the concentration of $\mathrm{Sr}$ was increased to $0.2 \mathrm{M}$, the size and number of crystals got decreased further. Thus the presence of excessive amount of 'Sr' suppresses the formation of nuclei and their further development into large crystals.
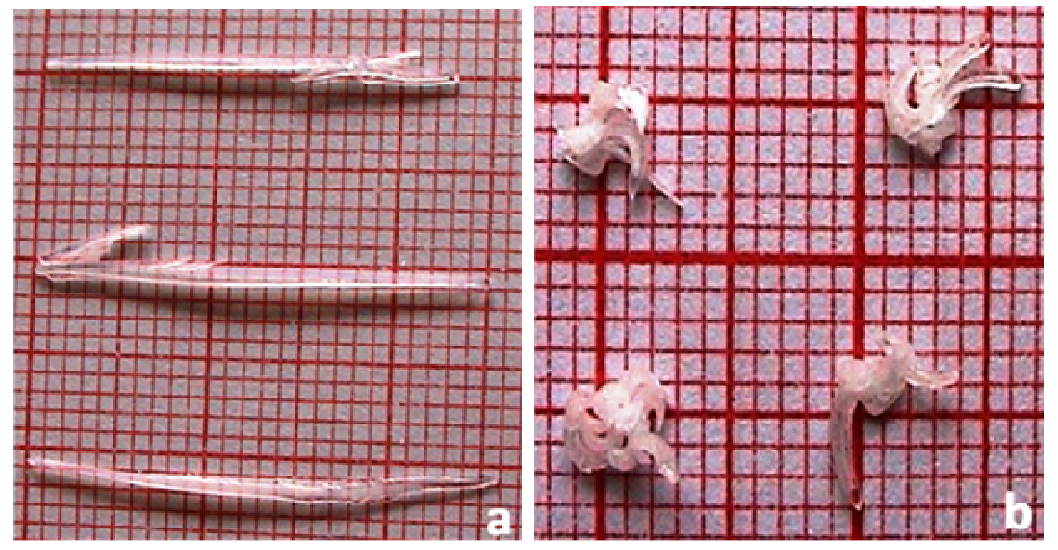

Fig. 2. As grown CHPD crystals (a) pure (b) $0.2 \mathrm{M} \mathrm{Sr}$

\subsection{Powder X-ray Diffraction Analyses}

The powder X-ray diffraction patterns were recorded for all the three types of products grown without the addition of strontium i.e. the thick white precipitate formed at the gel- solution interface, spherulitic and needle shaped crystals grown beneath the interface. The white precipitate was identified as hydroxyapatite (JCPDS data (09-0432) [Fig.3].

The spherulitic crystals were found to be a mixture of monetite (JCPDS data (70-1425)) and brushite. Fig. 4a shows the powder XRD pattern of monetite crystals grown without $\mathrm{Sr}$. The minor peaks observed at $2 \theta$ values $11.76^{\circ}$ and $21.05^{\circ}$ could be indexed for $\left(\begin{array}{lll}0 & 2 & 0\end{array}\right)$ and $(1 \overline{2} 1)$ planes of CHPD. The intensity of these CHPD peaks increased with the addition of strontium as shown in Fig. 4b. It can also be noted that the peaks shift towards lower angle side which indicates that the 'Sr' enters into CHPD crystal lattice. 


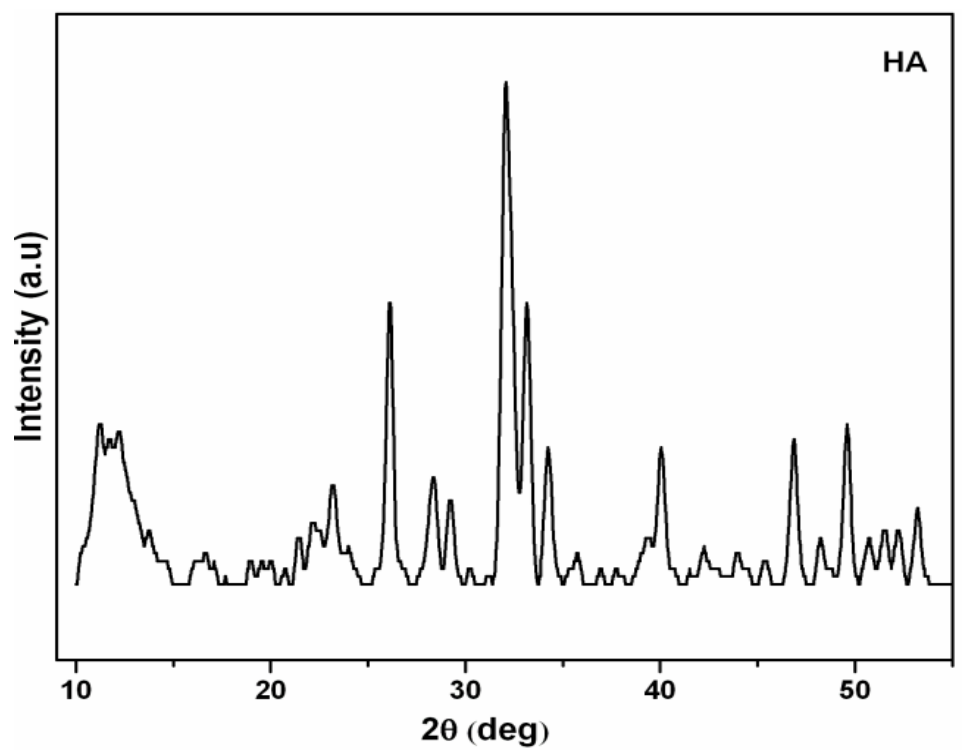

Fig. 3. Powder XRD pattern of hydroxyapatite

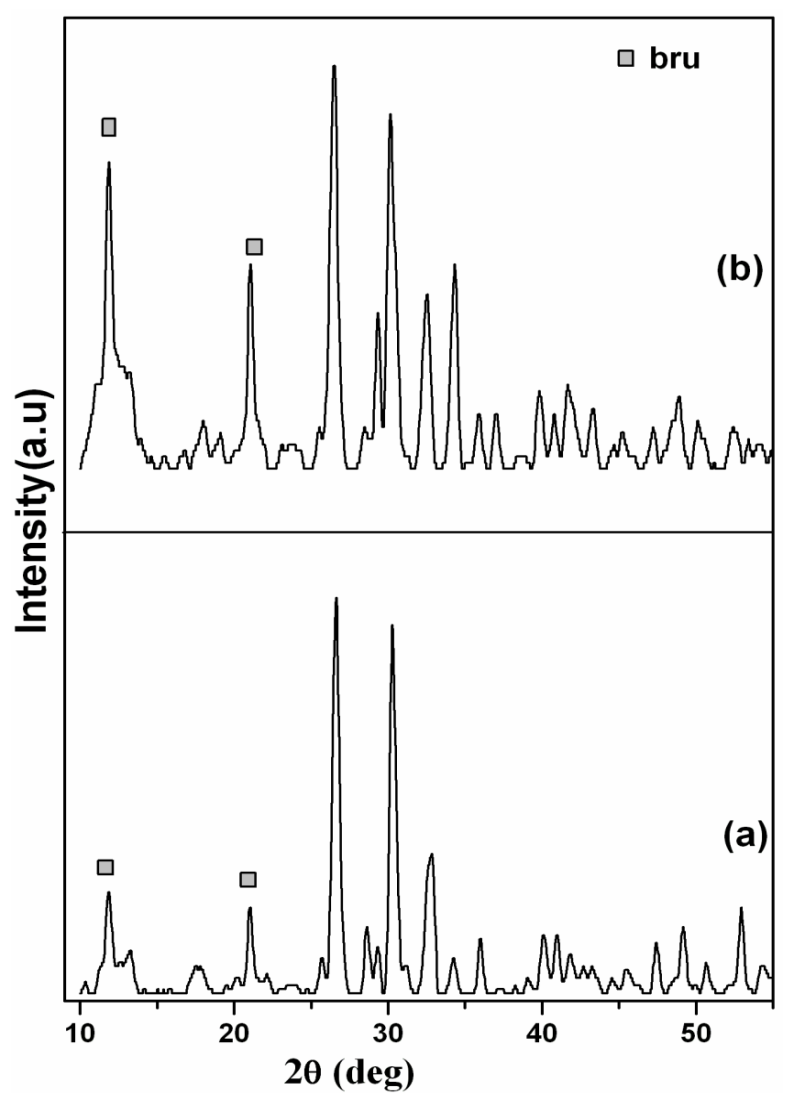

Fig. 4. Powder XRD patterns of monetite crystals (a) $0 \mathrm{M} \mathrm{Sr}$ and (b) $0.2 \mathrm{M} \mathrm{Sr}$ 
Fig. 5 shows the powder XRD pattern of the CHPD crystals grown without strontium (a) and with $0.1 \mathrm{M} \mathrm{Sr}$ (b) and $0.2 \mathrm{M} \mathrm{Sr}$ (c) respectively. The needle shaped crystals were identified as pure CHPD by comparing the JCPDS data (72-0713). The diffraction peaks of the crystals grown with Sr were strong and sharp when compared to that of pure system. This result indicates that the presence of Sr enhances the crystallinity of CHPD. A slight shift in the peak positions and change in peak intensity confirmed that the $\mathrm{Sr}$ replace a certain amount of $\mathrm{Ca}$ in CHPD.

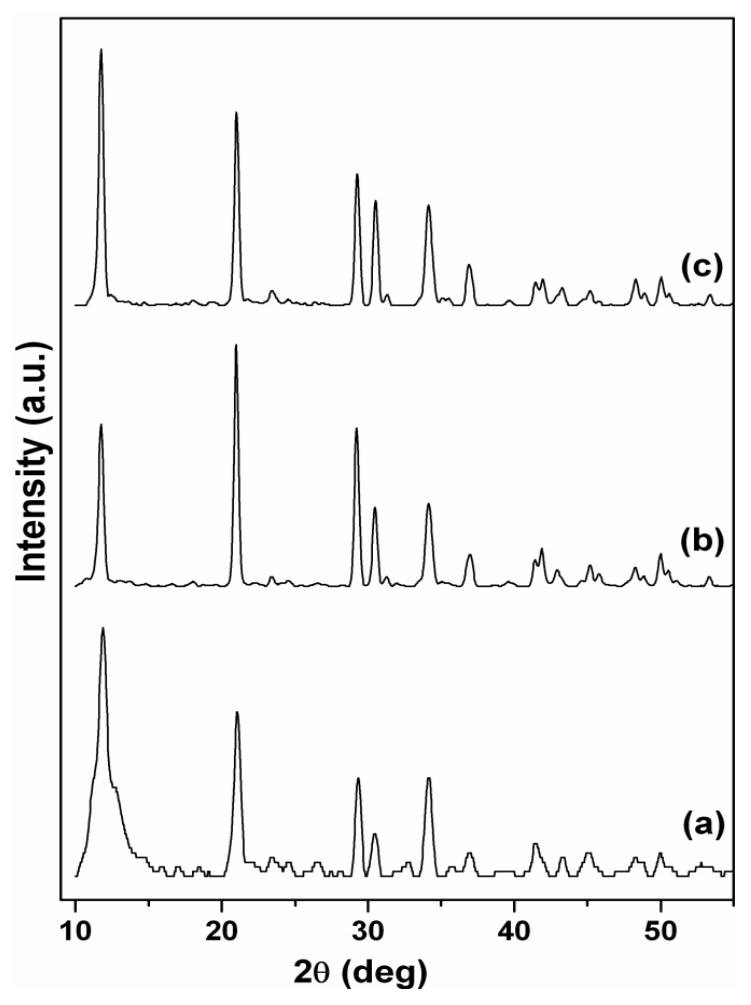

Fig. 5. Powder XRD patterns of CHPD crystals (a) $0 \mathrm{M}$, (b) $0.1 \mathrm{M}$, and (c) $0.2 \mathrm{M} \mathrm{Sr}$

As already reported by Bigi et al. ${ }^{[16]}$ the transformation of CHPD to HA was not observed in the present study. Instead Sr addition seems to suppress the crystallization of HA and the monetite was found to be the secondary phase.

The lattice parameters determined from the single crystal X-ray diffraction data obtained using four-circle Nonius CAD4 MACH3 diffractometer (MoK $\alpha, \lambda=0.71073 \AA$ ) are shown in Table 1. There was a small enhancement in the lattice parameters of $\mathrm{Sr}(0.2 \mathrm{M})$ grown CHPD crystals. This increase in lattice parameters could be due to the larger ionic radius of $\mathrm{Sr}(1.13 \AA \hat{A})$ when compared to that of $\mathrm{Ca}(1.00 \AA \hat{)})$. It may be that the $\mathrm{Sr}^{2+}$ provokes lattice distortions which expand the brushite crystal lattice ${ }^{[17]}$. 
Table 1: Lattice parameters of Pure and $\operatorname{Sr}(0.2 \mathrm{M})$ added CHPD crystals

\begin{tabular}{|c|c|c|c|c|c|}
\hline \multirow{2}{*}{ Samples } & \multicolumn{4}{|c|}{ Lattice parameters $(\AA)$} & \multirow{2}{*}{ Volume $\left(\AA^{3}\right)$} \\
\hline & $a$ & $b$ & $c$ & $\beta$ & \\
\hline Pure CHPD & 5.808 & 15.176 & 6.236 & 116.36 & 492.5 \\
\hline CHPD+0.2M Sr & 5.817 & 15.186 & 6.242 & 115.28 & 498.6 \\
\hline
\end{tabular}

\subsection{X-ray Fluorescence Spectrum}

X-ray fluorescence spectra of brushite crystals are shown in Figure 6 which reveals the presence of different elements such as $\mathrm{Sr}(\mathrm{K} \alpha=14.150 \mathrm{KeV}), \mathrm{P}(2.046 \mathrm{KeV})$ and $\mathrm{Ca}(\mathrm{K} \alpha=$ $\left.3.691 \mathrm{KeV}, \mathrm{K}_{\beta}=4.012 \mathrm{KeV}\right)$. In pure sample, the $\mathrm{Ca} / \mathrm{P}$ value was found to be very close to that of CHPD (1.00) according to the chemical formula. In doped crystals, $(\mathrm{Ca}+\mathrm{Sr}) / \mathrm{P}$ ratio was found to be 1.18 and 1.54 for the crystals grown with 0.1 and $0.2 \mathrm{M} \mathrm{Sr}$ respectively. As a consequence the stoichiometry is no longer maintained in case of Sr doping into CHPD.

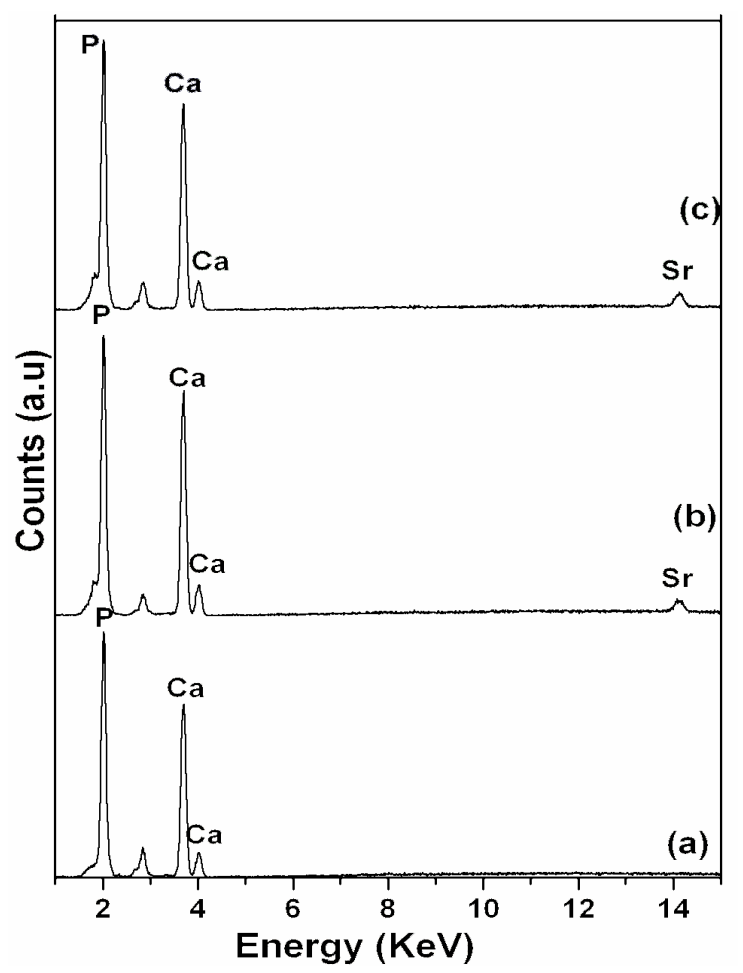

Fig. 6. X-ray fluorescence spectra of CHPD crystals (a) $0 \mathrm{M}$ (b) $0.1 \mathrm{M}$ (c) $0.2 \mathrm{M} \mathrm{Sr}$ 


\subsection{SEM analysis}

Fig. 7 shows the SEM images of octopus-like CHPD crystals grown in presence of $\mathrm{Sr}(0.2$ M). The crystals grown without 'Sr' have needle-like morphology. The surfaces were found to be fairly clean and defect free. On the other hand, the octopus-like crystals were found to be branched dendrites (Fig. 7a). The branches exhibited curved needle shapes which on further magnification showed the presence of large number of crystals arranged in eagle's wing-like shape (Fig. 7b). It may be that the presence of $\mathrm{Sr}$ enhances the nucleation process of CHPD in particular which results in innumerous crystals. Boanini et.al ${ }^{[18]}$ synthesized CHPD crystal and reported that a relatively low $\mathrm{Sr}$ replacement of $\mathrm{Ca}$ induces a decrease in the coherent length of the perfect crystalline domains and disturbs the shape of the crystals.
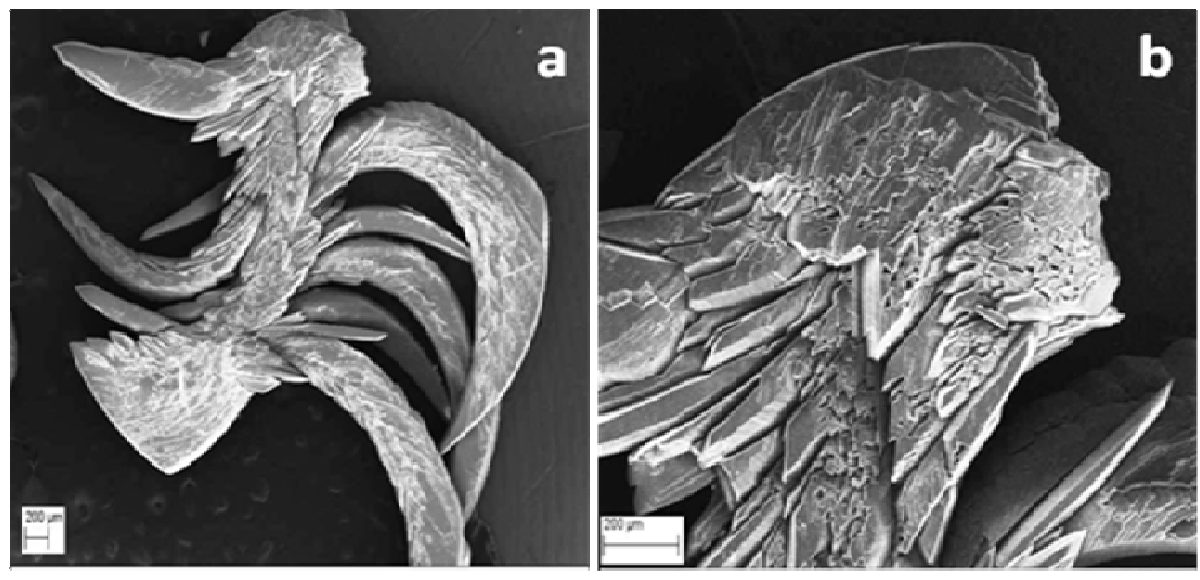

Fig.7. SEM pictures of CHPD crystal (a) pure (b) $0.2 \mathrm{M} \mathrm{Sr}$

\subsection{Thermal Analysis}

Figs. 8 and 9 illustrate thermal behavior of pure and strontium doped CHPD samples recorded in the temperature range between $30-1200^{\circ} \mathrm{C}$ at the rate of $20^{\circ} \mathrm{C} / \mathrm{min}$ in nitrogen atmosphere. In pure sample the weight loss occurs in two stages. The major weight loss of about $21 \%$ occurs between $103^{\circ} \mathrm{C}$ and $199^{\circ} \mathrm{C}$ which indicates the loss of lattice water. The endothermic peak in DTA around $128^{\circ} \mathrm{C}$ with the associated shoulders indicates the stepwise removal of water during this temperature range. In the region $\left(199-479^{\circ} \mathrm{C}\right)$, two molecules of $\mathrm{CaHPO}_{4}$ combine and result in the elimination of a water molecule leading to the formation of calcium pyrophosphate and nearly $74 \%$ of the sample is stable. The following chemical reactions are expected to occur during the dehydration and decomposition stages ${ }^{[14]}$.

$$
\begin{gathered}
2 \mathrm{CaHPO}_{4} \cdot 2 \mathrm{H}_{2} \mathrm{O} \rightarrow 2 \mathrm{CaHPO}_{4}+4 \mathrm{H}_{2} \mathrm{O} \uparrow \\
2 \mathrm{CaHPO}_{4} \rightarrow \mathrm{Ca}_{2} \mathrm{P}_{2} \mathrm{O}_{7}+\mathrm{H}_{2} \mathrm{O} \uparrow
\end{gathered}
$$


Nearly similar thermal behavior occurred in Sr doped CHPD also. The major weight loss of about $21 \%$ occurs between $110^{\circ} \mathrm{C}$ and $200^{\circ} \mathrm{C}$ in the crystals grown with $\mathrm{Sr}(0.2 \mathrm{M})$ addition. The mass loss corresponds well with the DTA results by the appearance of an endothermic peak at $178^{\circ} \mathrm{C}$ with the shoulders. Thus there is an increase in the peak temperature which indicates the improved thermal stability of CHPD due to Sr doping. In the second stage, nearly $8 \%$ weight loss occurs and the rest of the sample $(68 \%)$ was stable. The excess weight loss $(\sim 6 \%)$ may be due to $\mathrm{Sr}$ doping into CHPD.

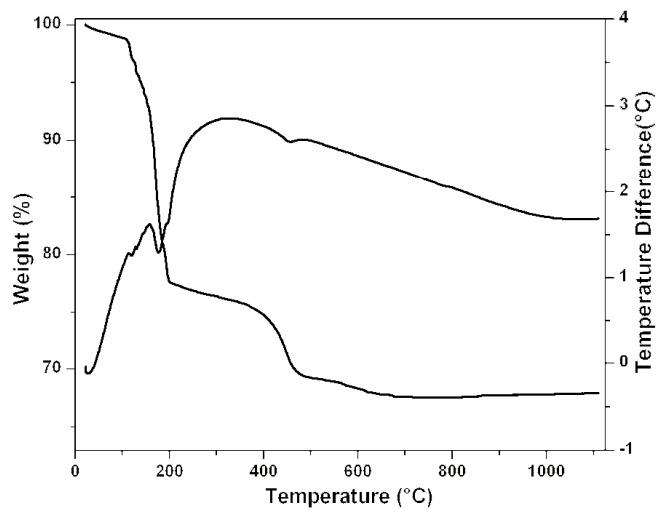

Fig. 8. TG-DTA curves CHPD

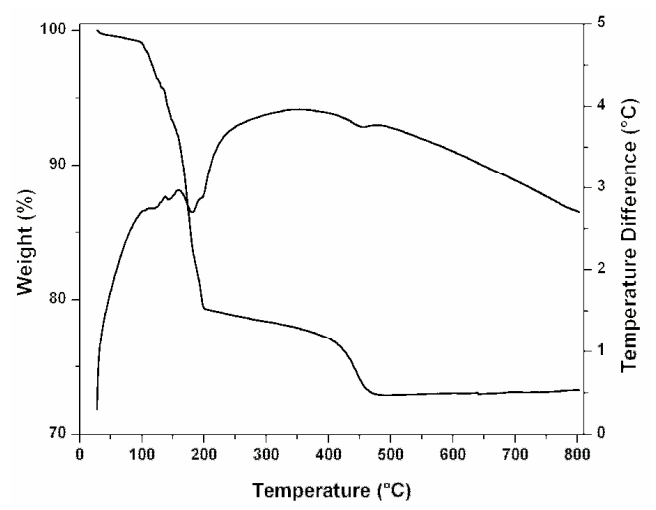

Fig. 9. TG-DTA curves of Sr doped CHPD

\subsection{FTIR Studies}

The recorded FTIR spectra for pure and Sr doped CHPD crystal were depicted in Fig. 10. The observed wave numbers, relative intensities and the assignments proposed for the crystals under investigation were found to be in good agreement with the reported literature ${ }^{[19,20]}$.

In the spectrum of pure CHPD, we can find two intense doublets; one with components at 3544 and $3489 \mathrm{~cm}^{-1}$ and the other with components at 3284 and $3168 \mathrm{~cm}^{-1}$. In addition a weak band around $2371 \mathrm{~cm}^{-1}$ and a sharp strong band around $1652 \mathrm{~cm}^{-1}$ have been observed. These two doublets have quite different shapes; the high-wave number doublet consists of sharp bands whereas the low-wave number doublet is much broader. The appearance of these two doublets is attributed to the existence of two different types of water molecules in the unit cell of brushite ${ }^{[19]}$. Petro et al. ${ }^{[21]}$ reported that the high-wave number lines are due to a loosely bound water molecule and the low wave number doublet to vibrations of those water molecules which, according to the crystallographic data of Beevers ${ }^{[22]}$, forms direct bonds to calcium atoms. In the $\mathrm{Sr}$ doped brushite, the low wave number doublets (3284 and $3168 \mathrm{~cm}^{-1}$ ) are slightly broadened and the peaks are shifted to 3295 and $3171 \mathrm{~cm}^{-1}$ respectively. This may be due to the presence of strontium. In case of high wave number doublet the intensity of peaks got reversed in the doped samples when compared to that of pure sample. 


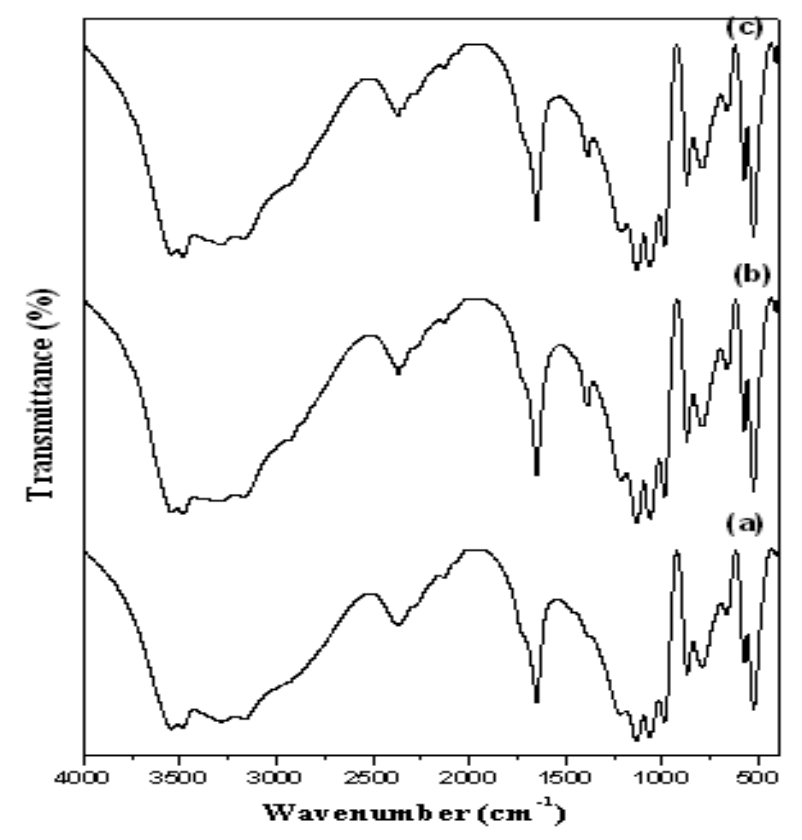

Fig. 10. FTIR spectra of CHPD crystals (a) $0 \mathrm{M}$ (b) $0.1 \mathrm{M}$ (c) $0.2 \mathrm{M}$.

Presence of sharp band around $872 \mathrm{~cm}^{-1}$ in all IR spectra confirms the brushite mineral phase [19]. The sharp and strong band around $1652 \mathrm{~cm}^{-1}$ is assigned to the in-plane bending of water molecules. CHPD is characterized by the splitting of phosphate bands in the region below $1600 \mathrm{~cm}^{-1}$ with more doublets. At $989 \mathrm{~cm}^{-1}$ a strong P-O stretching mode $\left(v_{1}\right)$ is observed. In the present work, the two bands at 576 and $527 \mathrm{~cm}^{-1}$ were assigned to the $v_{4}$ mode vibration. Peak intensity of hydrogen bonded $\mathrm{HPO}_{4}{ }^{2-}$ ions at $1387 \mathrm{~cm}^{-1}$ in the case of pure sample ${ }^{[23]}$ increases significantly in the $\mathrm{Sr}$ doped samples. The peak around $1215 \mathrm{~cm}^{-1}$ in the spectrum is due to $\mathrm{O}-\mathrm{H}$ in plane bending of $\mathrm{HPO}_{4}$ group. The peaks around 795 and $666 \mathrm{~cm}^{-1}$ are due to librations of water molecules and peak $795 \mathrm{~cm}^{-1}$ is assigned to a rocking and the $666 \mathrm{~cm}^{-1}$ peak to a wagging librational motion respectively. No major shifts or additional peaks are found in the case of $\mathrm{Sr}$ doped samples.

\section{CONCLUSION}

Simultaneous crystallization of calcium phosphates (brushite, hydroxyapatite, and monetite) has occurred in sodium metasilicate gel under physiological conditions. The presence of $\mathrm{Sr}$ has suppressed the formation of HA and promoted the monetite and brushite formation. In addition, a significant change in morphology of CHPD from needle shape to octopus-like shape has been observed. The XRD and XRF analyses confirmed the incorporation of Sr into brushite crystallites. TG-DTA studies confirmed the improvement in thermal stability of brushite due to $\mathrm{Sr}$ doping. 


\section{ACKNOWLEDGEMENT}

The authors wish to thank Dr. A. Tamizhavel, Tata Institute of Fundamental Research, Mumbai, for SEM and XRF analyses. K. Suguna thanks Dr. E. K. Girija for her helps in data analysis.

\section{REFERENCES}

1. Ryu, H.S., Youn, H.J., Sun Hong, K., Chang, B.S., Lee, C.K., Chung, S.S., 2002, “An improvement in sintering property of $\beta$-tricalcium phosphate by addition of calcium phosphate." Biomaterials, vol.23, pp. 909-914.

2. Tadayyon, A., Arifuzzaman, S.M., Rohani, S., 2003, "Reactive Crystallization of Brushite under Steady State and Transient Conditions: Modeling and Experiment." Ind. Eng. Chem. Res., vol. 42, pp. 6774-6785.

3. Pak, C.Y.C., Eanes, E.D., Ruskin, B., 1971, "Spontaneous Precipitation of Brushite in Urine: Evidence that Brushite is the Nidus of Renal Stones Originating as Calcium Phosphate." Proceedings of the National Academy of Sciences of the United States of America, vol. 68, pp. 1456-1460.

4. Moroz, T.N., Palchik, N.A., Dar, A.V., 2009, "Microelemental and mineral compositions of pathogenic biomineral concrements: SRXFA, X-ray powder diffraction and vibrational spectroscopy data." Nuclear Instruments and Methods in Physics Research Section A:Accelerators, Spectrometers, Detectors \&Associated Equipment, vol. 603, pp. 141-143.

5. Suresh, P., Kanchana, G., Sundaramoorthi, P., 2009, "Growth and Characterization Studies of MnHP Single Crystal in Silica Gel Medium.” J. Minerals Materials Characterization Engineering, vol. 8, pp. 349-357.

6. Lundager Madsen, H.E., 2008, "Influence of foreign metal ions on crystal growth and morphology of brushite $\left(\mathrm{CaHPO}_{4}, 2 \mathrm{H}_{2} \mathrm{O}\right)$ and its transformation to octacalcium phosphate and apatite." J. Cryst. Growth, vol. 310, pp. 2602-2612.

7. Sekar, C., Kanchana, P., Nithyaselvi, R., Girija, E.K., 2009, "Effect of fluorides (KF and $\mathrm{NaF}$ ) on the growth of dicalcium phosphate dihydrate (DCPD) crystal." Mater. Chem. Phys. vol. 115, pp. 21-27.

8. Sivakumar, G.R., Narayana Kalkura, S., Ramasamy, P., 1999, "Effect of magnesium on the crystallization and hardness of dicalcium phospahate dihydrate." Mater. Chem. Phys. vol. 57, pp. 238-243.

9. Legeros, R.Z., 1972, "Brushite crystals grown by diffusion in silica gel and in solution." J. Cryst. Growth, vol. 13-14, pp. 476-480.

10. Pors Nielsen, S., 2004, "The biological role of strontium.” Bone, vol. 35, pp. 583-588.

11. Verberckmoes, S. C., De Broe, M.E., D' Haese, P.C., 2003, "Dose-dependent effects of strontium on osteoblast function \& mineralization.” Kidney Int. vol. 64, pp. 534-543.

12. Bazin, D., Carpentier, X., Brocheriou, I., Dorfmuller, P., Aubert, S., Chappard, C.,Thiaudiere, D., Reguer,S., Waychunas,G., Jungers, P., Daudon, M., 2009, "Revisiting the localization of $\mathrm{Zn}^{2+}$ cations sorbed on pathological apatite calcifications made through X-ray absorption spectroscopy .” Biochimie. vol.91, pp. 1294 -1300. 
13. Kalkura, S.N., Vaidyan, V.K., Kanakavel M., Ramasamy, P., 1993, "Crystallization of uric acid.” J. Cyst. Growth, vol. 132, pp. 617-620.

14. Joshi, V.S., Joshi, M.J., 2003, "FTIR spectroscopic, thermal and growth morphological studies of calcium hydrogen phosphate dihydrate crystals." Cryst. Res. Technol., vol. 38, pp. 817-821.

15. Imai, H., Terada, T., Miura T., Yamabi, S., 2002, "Self-organized formation of porous aragonite with silicate.” J. Cryst. Growth, vol. 244, pp. 200-205.

16. Bigi, A., Gazzano, M., Ripamonti, A., Roveri, N., 1988, "Effect of foreign ions on the conversion of brushite and octacalcium phosphate into hydroxyapatite." J. Inorg. Biochem., vol. 32, pp. 251-257.

17. Hamdan Alkhraisat, M., Tamimi Marino, F., Rueda Rodriguez, C., Blanco Jerez, L., Lopez Cabarcos, E., 2008, "Combined effect of strontium and pyrophosphate on the properties of brushite cements.” Acta Biomaterialia, vol. 4, pp. 664-670.

18. Boanini, E., Gazzano, M., Bigi, A., 2010, "Ionic substitutions in calcium phosphates synthesized at low temperature.” Acta Biomaterialia, vol. 6, pp. 1882- 1894.

19. Sauer, G.R., Zunic, W.B., Durig, J.R., Wuthier, R.E., 1994, "Fourier transform raman spectroscopy of synthetic and biological calcium phosphates." Calcif. Tissue. Int. vol.54, pp. 414-420.

20. Xu, J., Butler, I.S., Gilson, D.F.R., 1999, “FT-Raman and high-pressure infrared spectroscopic studies of dicalcium phosphate dihydrate $\left(\mathrm{CaHPO}_{4} \cdot 2 \mathrm{H}_{2} \mathrm{O}\right)$ and anhydrous dicalcium phosphate $\left(\mathrm{CaHPO}_{4}\right)$." Spectrochim. Acta Part A, vol. 55, pp. 2801-2809.

21. Petrov, I., Soptrajanov, B., Fuson, N., Lawson, J.R., 1967, "Infra-red investigation of dicalcium phosphates." Spectrochim. Acta. A, vol. 23, pp. 2637-2646.

22. Beevers, C.A., 1958, "The crystal structure of dicalcium phosphate dihydrate, $\mathrm{CaHPO}_{4} .2 \mathrm{H}_{2} \mathrm{O}$.” Acta Cryst., vol.11, pp. 273-277.

23. Berry, E.E., Baddiel, C.B., 1967, “ The infra-red spectrum of dicalcium phosphate dihydrate(brushite)." Spectrochim. Acta. A, vol. 23, pp. 2089-2097. 